\title{
Survival of the Fattest
}

\author{
M. H. Saier • J. T. Trevors
}

Received: 15 June 2009 / Accepted: 16 June 2009 / Published online: 20 August 2009

(C) The Author(s) 2009. This article is published with open access at Springerlink.com

Survival of the fattest contrasts with, but in some respects resembles, the suffering and premature deaths of the leanest humans. We refer here to the imbalance between affluent, resource consuming, globally polluting, and often wasteful and greedy humans as opposed to the hungry and impoverished people of the world who live on less than one or two dollars per day. The irony is that a life of excess is almost as damaging to the human animal as is a life of insufficiency. Still, the wealthy continue to seek more, presumably to guarantee that they will continue to live a "life of Riley" - a life of plenty. But in the process, they are endangering their own health, depriving their children of parental guidance and security, exasperating our environmental crises and ignoring the rights of others including those of their own offspring and all future generations. Theirs is the epitome, the embodiment, the quintessence of selfishness which eventually leads to health problems that have come to plague so many of us. Meanwhile, the

M. H. Saier $(\bowtie)$

Division of Biological Sciences, University of California, San Diego,

La Jolla, CA 92093-0116, USA

e-mail: msaier@ucsd.edu

J. T. Trevors $(\bowtie)$

Department of Environmental Biology,

University of Guelph,

Guelph, ON NIG 2W1, Canada

e-mail: jtrevors@uoguelph.ca impoverished one third of the human population lack access to the basic rights that a majority of us in the developed and semidemocratically governed countries normally take for granted.

We maintain that our basic human rights include the right to "health, liberty and the pursuit of happiness." As Thomas Jefferson idealistically enunciated: "Equal rights for all, special privileges for none." Our world is sadly very far from this ideal. The right to life, liberty, and justice requires the availability of health care, and proper health care implies adequate professional services, vaccinations, and above all, an acceptable level of sanitation without life-threatening pollution. While these services are not fully available to any of us, they are certainly not available to about one third of the Earth's human population. It is shocking to realize that they are also not available to at least $15 \%$ of Americans. Americans neglect the world, being the greatest consumers and polluters, but they also neglect their own people.

Disease preventative measures are, in the long run, far less costly than attempts to cure existent illnesses. We need far-sighted politicians who do not think only of the moment. They must take the probable future consequences of their actions into account. They must be able to think beyond the next election and their personal preferences; their actions must reflect the needs of the people rather than their own selfish interests or those of their families. This is a most 
serious problem, since in the USA, and probably many other countries as well, the carrot corporations hold out to our governmental representatives amounts to hundreds of thousands of dollars per year. Unfortunately, politics is profitable, and this gives corporations power over the people. Should there not be laws against this? Since when is a corporation deserving of the legal status of a citizen? Hamlet noted that "Something is rotten in the State of Denmark," a reflection of his perception of his times and country, and as the play unfolds, we come to realize that he was right. But today, "Something is rotten in the state of current democracies." We all know it, but we feel powerless to correct the inequities and injustices that plague our forms of governance. Still, we need to accomplish more. Our representatives must be competent! They must be able to evaluate scientific data and sociological surveys, and then they have to be willing to use these as their guides for the implementation of sound policies. To allow the realization of these goals would best serve all citizens of a country and, indeed, all world citizens as well. The goal of comprehensive health care has, for example, been achieved to some degree in almost all developed countries as well as many developing countries.

However, of even greater importance, if we are to ever achieve sustainability, with an absolutely essential and concomitant decline of the human population, it is necessary to provide universal free birth control services including a variety of methodologies since any one woman may be restricted to just a few such methods. Without these services, no woman has personal freedom and without them, no country has, or is ever likely, to achieve replacement level fertility. Over 100 studies conducted in different countries have shown that without these rights, no county can stabilize its population. The availability of these together with a minimal amount of education, namely enough so that the women of a country understand the benefits of reduced family size, and a knowledge of how to use the devises, is all that it takes to achieve replacement level fertility. Compulsion is not required, and abstinence simply does not work. Realistic goals are essential, and a knowledge of the surveys that reveal the truth is essential in planning policy. We highly recommend our readers examine the article by M. Campbell, N. N. Sahin-Hodoglugil and M. Potts, "Barriers to fertility regulation: a review of the literature," published in the journal, Studies in Family Planning, vol. 37, issue 2, pages 87-98 (2006) for an in-depth treatment of these issues.

There are other important services that enhance personal freedom and allow efficient use of human resources. Food, clothing, and shelter are necessary to generate feelings of security. These cannot be available to all or most of the human population unless we bring down our numbers. Remember that $1-2$ billion people on this planet are already undernourished. To lead healthy lives without premature mortality, we need protection from pollution of our waterways, oceans, soils, our food, and our atmosphere. Proper sewage treatment and the availability of potable water will also be necessary, and these can only be achieved with a diminishing global population. Widespread ownership of land, not by a few, but by many, and sustainable local farming practices will promote health and environmental protection. To be sure, this list is not complete, but the most important points have been made. The avoidance of human suffering and premature death will require that the affluent fattest gain a conscience and act upon that conscience by consuming fewer resources and polluting the environment to a much lesser degree. Our global economy must take into account the "hidden costs" that include the loss of human health and dignity. To correct these ills will require that both the fattest and the thinnest act rationally to optimize both their own lives and those of others.

Supercapitalism is far from being a perfect economic system, especially when it involves fear, greed, and corruption. When corporations make the profits they think they deserve, they then rationalize their acts by noting that the economy is growing. After all, goods and services are being consumed and provided. When the economy falters, and corruption and mismanagement are the causes, the economy slides into a recession, and some, sometimes many, of the once mighty corporations become corporate welfare recipients. They of course consider this clever. They think they cannot lose. But they and their stock holders do lose, particularly in the extreme when they go bankrupt. Even more importantly, their children and grandchildren lose as well, but their losses are far greater and far more reaching. What do corporate leaders not understand or do not care about if they do understand? It is that no amount of corporate and/or personal wealth will protect them from global 
pollution, a lack of nonrenewable resources, food, water and energy shortages, and disruption of social infrastructure. To follow the profit motive alone spells disaster. There is something far more valuable to protect.

You cannot purchase what is not for sale. You cannot stockpile an unpolluted global environment for the days when you need it. Nobody in any economic class will be spared from global climate change. With too many humans on the planet, we know that conditions of Earth will continue to deteriorate. Droughts, heat waves, extreme weather fluctuations, pollution, failing infrastructure, and resource shortages will be the consequences. Even the fattest, most affluent members of society will suffer. Nature simply does not discriminate based on economic class; it treats everyone the same. The beach front properties and coastal cities will be under meters of water and will be valueless. Have you ever attempted to relocate coastal mega-cities, each with 10 million inhabitants?

Survival of the affluent fattest never was a correct humanitarian approach to the world's problems. It is a human-made system based on greed, fear, competition, and war. The old colonial empires are gone, but the problems created remain and are becoming continually worse as our human populations increase. Nominally, slavery is largely gone, but the aftermath of slavery was racism, and it still remains in the minds and actions of many. The fattest may live longer than the leanest, but they will not survive; their air conditioners will pollute all the more. And the weakest, always in need, will, in general, survive even less long, although given their numbers, they may be the last to go. Who knows, the prophesy that "The Meek shall Inherit the Earth" may, in the end, prove true. Regardless, the smartest will perish with the dumbest. Nature will select severely using global climate change as just one of the selective forces for destruction. It may be that cultures that currently have traditionally low environmental impact life styles will last longer, but hey, remember, we are all in this together. Technology cannot cure all of our global pollution problems unless we eliminate global human population growth. We need time to arrive at the correct, sustainable solutions. So far, we are not doing too well.

In a speech to a graduating college class, and later published in the New York Times in 1979, Woody Allen remarked:

"More than at any other time in history, mankind faces a crossroads. One path leads to despair and utter hopelessness. The other, to total extinction.... Unfortunately, our politicians are either incompetent or corrupt. Sometimes both on the same day. The Government is unresponsive to the needs of the little man. Under five-seven, it is impossible to get your congressman on the phone. I am not denying that democracy is still the finest form of government. In a democracy at least, CIVIL LIBERTIES ARE UPHELD; NO CITIZEN CAN BE WANTONLY TORTURED, IMPRISONED, or made to sit through certain Broadway shows...

Overpopulation will exasperate problems to the breaking point. Figures tell us there are already more people on Earth than we need to move even the heaviest piano. If we do not call a halt to breeding by the year 2000 , then there will be no room..."

So prophetic, for two reasons: First, he (and others) foresaw then what many of us are only now coming to realize, and second, in being an environmentalist, and no matter how serious matters are, it is always best to keep a sense of humor.

Open Access This article is distributed under the terms of the Creative Commons Attribution Noncommercial License which permits any noncommercial use, distribution, and reproduction in any medium, provided the original author(s) and source are credited. 